[AXEL MOULINIER] $]^{1}$

Doutorando em História da Arte. École du Louvre, Paris.

E-mail: axel.moulinier@gmail.com

\title{
Incompreensões, desconfortos e escândalos na moda contemporânea ${ }^{2}$
}


0 escândalo na moda do século XX nunca deixou de ganhar visibilidade. Os anos 1980 são aqueles dos costureiros "superstars" ", lançados ao centro do furacão midiático. No decorrer do período compreendido entre 1980 e 2015, os olhos da opinião pública estiveram voltados para as Semanas de Moda, que despontaram nos quatro cantos do mundo. Nova York, Londres, Milão, Paris e uma infinidade de outras Semanas, mais periféricas e menos tradicionais, passaram, então, a pautar a moda internacional. Provavelmente, é também graças a esta nova visibilidade que o escândalo passou a ter uma maior dimensão na moda: a anorexia, por exemplo, é, dentre os debates ligados à área, um dos mais ativos na esfera pública, assim como o racismo na seleção de modelos e a objetificação dos corpos das mulheres. Em paralelo aos desfiles, quase sempre as coleções contam também com o suporte de uma campanha publicitária fotográfica. Como confessou Rei Kawakubo, "as fotos na imprensa ajudam enormemente» (MANESCEAU; PAILLE; SEZE, 1987). Desfiles e fotografias constituem-se, então, nos vetores essenciais para se observar o aspecto polimórfico do escândalo na moda durante as três últimas décadas.

\section{O choque japonês}

A partir de 1980, surge um novo fenômeno: a moda se torna sua própria censora, e os primeiros a serem questionados foram seus códigos. Em 1981, os japoneses Rei Kawakubo e Yohji Yamamoto chegam a Paris e apresentam suas primeiras coleções com trajes negros, destruídos, com aparência de não acabados. Suas coleções primavera-verão de 1983 de prêt-à-porter feminino escandalizaram os espectadores de tal forma que a imprensa as chamou de "duas coleções chocantes", de uma "ruptura absoluta com nossa visão ocidental» operada "pelo monge e pela kamikaze» (SAINDERICHIN, 1982) - em comparação com a criação francesa da época, encarnada por designers como Christian Lacroix ou Marc Bohan (para Christian Dior). Apenas doze anos após estes primeiros desfiles, a historiadora da moda Florence Müller considerou que Rei Kawakubo

causou escândalo [...] com coleções que pareciam fazer apologia ao feio e ao miserável. A coleção "dilacerada" de 1983 chocou particularmente [...]. Uma mesma incompreensão acolheu as coleções de Yohji Yamamoto, marcadas de um pauperismo sutil, associado a uma atmosfera de fim de mundo após os efeitos da bomba atômica. No entanto, os elementos de pesquisa destes criadores são muito mais inovadores do que seus efeitos escandalizadores. Frente à tradição europeia do cortado-e-costurado rente ao corpo, eles introduziram a amplidão, a destruição, e a assimetria foi rejeitada (MÜLLER, 1995, p. 561-562). 
Alguns anos mais tarde, em 1986, Yohji Yamamoto teria desejado ele mesmo deixar em estado de choque a alta-costura francesa: «Vir a Paris era simplesmente tentar uma nova forma de protesto. [...] Eu não imaginava que ela produziria tantos efeitos, nem que ela pudesse fazer escolan (LEFORT, 1986). A mudança embreada pelos criadores japoneses foi recuperada um tempo depois por jovens designers, a exemplo de Martin Margiela. $\mathrm{Na}$ inauguração de sua maison, em 1988, os trajes desconstruídos - como nós os chamamos hoje -, assinatura do costureiro belga, apareceram como um eco do choque japonês. Os desfiles de Margiela, acontecendo em espaços improvisados - por exemplo, um terreno vazio do $20^{\circ}$ arrondissement de Paris -, "provocadores, tanto na forma como no fundo, criam imediatamente o choquen (SÉPULCHRE, 1989), mas se tornam, no decorrer dos anos 1990, um evento incontornável da Semana de Moda parisiense, "um evento único nos anais da modan (DETAILS, 1990). Martin Margiela explica sua trajetória: «Eu detestei os anos 1980 e sinto necessidade de quebrar alguma coisa para dar início a 1990" (SÉPULCHRE, 1989). Ele criou, então, roupas descontruídas, reconstruídas, recicladas, destruídas, recosturadas, tudo cortado e costurado, tornando-se, assim, um herdeiro paradoxal da inovação japonesa e da tradição francesa.

Portanto, além da parte técnica, transgride-se também o sistema de apresentação da alta-costura. Distanciando-se cada vez mais dos desfiles codificados que ainda eram comuns na maison Christian Dior nos anos 1970, os jovens costureiros trazem um novo ritmo: a música é contemporânea, os modelos andam rápido, o desfile é encurtado. A apresentação com anúncio do modelo desfilado sofre o primeiro ataque quando, em 1973, Créateurs \& Industriels organiza seu primeiro desfile (GRUMBACH, 2006). Mas é sobretudo com Thierry Mugler que se tem a transgressão mais profunda deste sistema: em 1984, o desfile que ele apresenta é efetivamente um espetáculo, com ingressos colocados à venda 4 (EVANS, 2001, p. 301). Mugler inventa o desfile aberto stricto sensu e rompe com a tradição da alta-costura parisiense.

Alguns escândalos ocorridos no periodo de 1980 a 2015 parecem atestar a existência daquilo que o sociólogo Michel Offerlé (1998) batizou de "estratégias de escandalização». Um dos exemplos é o pornô-chique orquestrado por Carine Roitfeld nos anos 2000 nas páginas da Vogue Paris, com o apoio do criador americano Tom Ford e do fotógrafo peruano Mario Testino. A redatora-chefe e o diretor artístico da maison Gucci colocaram na ordem do dia esta corrente estética nascida no cinema pornográfico americano nos anos 1970. A crítica foi severa. A propósito do último desfile assinado por Tom Ford para a maison Yves Saint Laurent, em 2002, este último declarou: "Para mim, o 'pornô-chique' é uma ignomínia, é o que há de pior. É o horror propagado por uma pequena panelinha, um pequeno 
grupo da moda, que faz muito barulho, mas que está distante da vida" (CHAYETTE, 2008). Contudo, use tantas grifes [...] adotaram a 'transgressão provocante', parece que ela funcionan (GROUSSET, 2001). E, de fato, os executivos não deixaram de lado estas estratégias. Bernard Arnault, presidente-diretor geral do grupo de luxo francês LVMH, resolveu, em 1997, colocar os costureiros britânicos John Galliano e Alexander McQueen à frente das maisons mais clássicas do seu plantel: respectivamente, Christian Dior e Givenchy. Os escândalos aconteceram: do desfile sem modelos de Alexander McQueen às provocações de John Galliano, os dois criadores não pararam de dar o que falar a respeito de suas coleções e de suas personalidades cáusticas.

\section{0 corpo exibido}

0 corpo está profundamente situado no coração destes escândalos. No prêt-à-porterfeminino da temporada primavera-verão de 1997, Rei Kawakubo apresentou, para sua grife Comme des Garçons, a coleção intitulada Body meets Dress/Dress meets Body, com vestidos em elastano formados por estruturas com enchimentos, criando deformações. A Vogue americana (BETTS, 1998) classificou estes Bump Dresses entre "as piores criações de 1997", pois, "em vez de valorizar as partes do corpo historicamente percebidas como femininas ou sensuais, e de dissimular as partes percebidas como não-atrativas, as protuberâncias fazem exatamente o contrário" (BETTS, 1998). Gérard Lefort escreveu uma crítica para o Libération na qual as palavras têm um sentido bastante pesado:

Rei Kawakubo [...] manifestamente estabeleceu um importante diálogo com ela mesma, chegando à "perturbadora" conclusão de que a feminilidade tinha "algo a ver em algumas partes" com a deformidade. [...] as jornalistas ficaram um bom quarto de hora paralisadas, com suas Mont-Blanc penduradas. É preciso dizer que, excepcionalmente, compartilhamos sua dúvida existencial quanto à pertinência da proposta da criadora. Com efeito, na Comme des Garçons do verão de 1997 a tendência é mais "Como Corcundas"5 (de Notre-Dame). Parece que algum tipo de almofada ou de airbag (vai saber?) foi enfiado à força sob as roupas, formando bolhas, excrecências e outros tumores de tecido bastante volumosos. Com sorte, seria possivel eventualmente ver ali um tipo de Crítica da razão pura ${ }^{6}$ das próteses e artifícios dos quais a moda usa e abusa, um tipo de almofada em Wonderbra. Ou está além do embaraçoso, pois pode-se também detectar ali um curioso fantasma de mulher ontologicamente monstruosa: uma fada malévola, uma elephant-woman imaginada por um David Lynch em má forma e amarrada por um Christo ${ }^{7}$ pouco inspirado (LEFORT; BOULAY, 1996). 
Por fim, a Vogue Paris escreve em sua edição de dezembro 1997/janeiro 1998: "Provocando uma onda de choque que se propagou justamente no coração da nossa revista. [...] Seus modelos tinham despertado a incredulidade dos nossos leitores, que se perguntavam qual poderia ser a sua utilidade" (ON, 1997/1998). As críticas são amargas, proporcionais ao choque ocasionado pelos corpos deformados que haviam desfilado algum tempo antes em Paris. Já a coleção de alta-costura Les insects, de Thierry Mugler (primavera-verão 1997), que "explora um novo universo, aquele das mulheres-inseto" (L'UNIVERS, 1997), é acolhida ironicamente pela critica. Le Figaro se pergunta: "[...] quem vai querer se vestir de besoura ou de inseto-fêmea [...]?" e conclui que "Sim, Mugler é um gênio, mas ele o estraga por seu gosto pelas HOs, sua paixão por Cruela Cruel, suas flertadas com o sadomasoquismo. E isso incomoda" (J. S., 1997). Como explica Véronique Bergen, escritora e filósofa, "[...] os hibridismos não são permitidos. MuIheres-girafa [...], homens-flores se exibem sobre as passarelas, mas se, em princípio, as mulheres-lua [...], os homens-estrela são possiveis, eles não têm, de fato, direito à cidade" (BERGEN, 2013, p. 133-134).

Desde os anos 1960, a nudez assume um papel cada vez mais importante na criação das roupas. Para a coleção de alta-costura outono-inverno 1968-1969, Yves Saint Laurent realizou o See-through dress, um de seus famosos vestidos transparentes (HAYE; MENDES, 2011[2000], p. 195). "Símbolo do rock e da sua ideia de transgressão, o torso nu exibido em cena invadiu os desfiles e as reportagens de moda, infiltrando-se também nos videoclipes e na alta-costura" (CALETTI, 2006, p. 86). Mesmo onipresente na moda, raramente a nudez provoca indiferença. Para sua coleção prêt-à-porter feminina da primavera-verão 1998, Hussein Chalayan apresentou seis modelos na entrada final: a primeira estava nua e cada uma das seguintes vestia um niqab cada vez mais longo, até chegar na última, de burqa. "Trata-se de um desfile de moda, de arte conceitual, um manifesto político, uma simples provocação?", pergunta-se a Vogue Paris (RACHLINE, 1998). Face ao confronto entre corpo nu e véu, entre nudez e religião, "não é preciso dizer que, além das lágrimas de alguns convidados, também havia alguma consternação" (WHITE, 1998). Na ocasião da apresentação da coleção prêt-à-porter masculina de outono-inverno 2015-2016 de Rick Owens, um recorte na parte frontal do traje de alguns modelos deixava seus pênis visíveis aos espectadores. "Rick Owens literalmente lançou as bolas para a linha de frente" (HUON, 2015) antes de inflamar as redes sociais (PFEIFFER, 2015). Diante desta "escandalosa coleção Nudez" (W IN WONDERLAND, 2015) e das inúmeras zombarias dirigidas ao designer, é forçoso constatar que, em 2015, não é aceitável mostrar um pênis na passarela, assim como não o era mostrar a genitália feminina em 1998. A historiadora da moda Aileen Ribeiro nos ajuda a compreender isso: 
Apesar da quebra de inúmeros tabus e do culto deliberado aos corpos expostos, [...] existe ainda um forte consenso em torno do princípio de "decência" das roupas, que consiste em estabelecer um limite para a exposição dos órgãos sexuais primários. Por estarmos ainda ancorados em nossa herança judaico-cristã no que diz respeito a isso, não é possivel ver mudanças profundas em nossas atitudes (RIBEIRO, 2003, p. 171).

0 corpo da moda é conhecido como um "corpo glorioso" no sentido bíblico (BERGEN, 2013). Intocável, profundamente diferente do corpo do "joão-ninguém", o corpo dos manequins não pode estar fora das normas. John Galliano desfilou para sua própria maison, na primavera-verão 2006,

\footnotetext{
uma coleção vestida por anões e por gigantes, por pessoas gordas e magras, jovens e velhas, bonitas e feias. A despeito da carta-manifesto colocada nas cadeiras reivindicando o direito à moda para todos, pois "todo mundo é belo", um certo número de profissionais sentiu-se profundamente chocado por este ponto de vista (DAYAN, 2006).
}

Como conta Cathy Horyn: "Um jovem e respeitável jornalista francês me perguntou após o desfile o que eu havia achado 'daqueles monstros' [...] Ele acrescentou que as pessoas sentadas próximas a ele haviam rido na cara dos manequins" (HORYN, 2005). No mundo da moda, não há lugar para o corpo anormal - ou seja, para aquele que não respeita as normas.

\section{Os sujeitos-tabus}

A História contemporânea possui um patrimônio que é difícil de explorar. As coleções que remetem de perto ou de longe à Segunda Guerra Mundial foram sempre recebidas com severidade. 0 desfile de prêt-à-porter feminino de outono-inverno 1977-1978 de Claude Montana foi taxado pela imprensa como "neonazista" (DUKA, 1978). Rei Kawakubo apresentou para o prêt- $\dot{a}$-porter masculino de outono-inverno 1995-1996 uma coleção intitulada poeticamente de Sommeil ("Sono"). No artigo "A estilista que causa escândalo" (HENNO, 1995), publicado alguns dias mais tarde, Le Figaro a condena por ter se inspirado nos uniformes usados pelos deportados do campo de concentração de Auschwitz para confeccionar as peças da coleção. Os pijamas listrados vestidos por manequins de pele emaciada tornaram difícil não lembrar das imagens dos deportados judeus presos nos campos da morte. Serge Cwajgenbaum, secretário-geral do Congresso Judeu Europeu, declarou que estes modelos "despertam imagens de pesadelo e banalizam eventos que abalaram o mundo cinquenta anos atrás" (ROMILLAT, 1995).

As religiões e as tradições são igualmente setores intocáveis. A coleção de inspiração Maori de Paco Rabanne para a alta-costura primavera-verão 1998 foi considerada uma "apropriação indelicada" (MOKO, 1999) de motivos tradicionais sagrados. Já a coleção Les rabbins chics, de 
Jean-Paul Gaultier para o prêt-à-porter feminino outono-inverno 19931994, inspirada nos hábitos usados pelos judeus ortodoxos de Nova York, foi apresentada em uma atmosfera tensa (SPINDLER, 1993a). Alguns anos mais tarde, por ocasião de uma exposição retrospectiva, Gaultier reconheceu que "algumas imagens foram mal compreendidas pelos fundamentalistas, que acreditavam que as manequins tinham sido 'fantasiadas' como eles. Eles também estavam irritados pelo fato de roupas de rabino estarem sendo usadas por mulheres" (LORIOT, 2011, p. 316). A imprensa genérica americana nos confirma, uma temporada depois do dito desfile, que "[...] se inspirar na religião continua a ofender. Foi exatamente isso que aconteceu na primavera passada quando o designer Jean-Paul Gaultier ornamentou seus ternos pretos de lã com os paramentos dos Judeus hassídicos" (SPINDLER, 1993b). No entanto, levando em conta outras fontes, convém relativizar este escândalo; grandes periódicos judaicos internacionais consideraram que "Gaultier é um homem íntegro" (COHEN, 1993) e qualificaram a coleção como "inesquecivel" (JEAN-PAUL, 1993).

A condição humana em sua concepção mais ampla também é objeto de tabu. É isso que mostram a coleção inspirada nas pessoas em situação de rua de John Galliano para Christian Dior (alta-costura, primavera-verão 2000) e a coleção Highland Rape (prêt-à-porter feminino, outono-inverno 1995-1996), de Alexander McQueen, apresentando mulheres metaforicamente violadas. No ano 2000, a apresentação da pré-coleção da maison Dior provocou "uma tempestade em copo d'água" (SAMET, 2000). Os trajes desestruturados foram inspirados naqueles das pessoas que não têm onde morar. "A dama e o vagabundo versão Galliano sobressaltou os editores, agitou os redatores, sufocou os clientes" (SAMET, 2000), tudo isso deliciando Bernard Arnault, que considera esta coleção como "uma obra de arte", à qual ele "adere completamente" (SAMET, 2000). A imagem da maison Christian Dior é associada ao classicismo e à grande tradição da alta-costura francesa. Assim, quando um criador decide se inspirar em um tema tão politicamente incorreto, "ofuscar as boas maneiras - lançar uma moda 'mendigo' quando se tem 6 milhões de desempregados - é inadmissivel" (SAMET, 2000). Sobre a coleção Highland Rape, as jornalistas do The Independent entenderam que "os vestidos rasgados na altura do seio" usados por manequins "vítimas de estupros coletivos" eram "uma piada doentia". Elas viram na coleção um insulto às mulheres e até mesmo ao talento do criador (HUME; BLANCHARD, 1995). Taxado de misógino, este desfile permanece como um dos mais importantes, e dos mais criticados, da carreira de Alexander McQueen.

Se jamais houve uma sociedade sem tabus e se é preciso uma boa dose de má-fé ou de ignorância histórica para gritar pela inquisição, não é menos verdadeiro que as democracias [...] estão sempre sob a ameaça de um novo despotismo: a tirania da opinião (BLAIN, 2012). 
0 "politicamente correto" é uma das manifestações desta "tirania da opinião". Antes de se tornar uma simples expressão do senso comum, 0 politicamente correto, nascido nos anos 1980, era um movimento contestatório que promovia o direito à diferença e ao reconhecimento das minorias sociais nos Estados Unidos. Seus valores originais foram revirados e, no lugar de criar uma maior tolerância, a doutrina foi recuperada com o objetivo de estigmatizar na esfera pública os comportamentos julgados inaceitáveis. As consequências deste movimento de pensamento invadiram o campo da moda e fizeram-na refém dele.

Apesar disso, o escândalo parece necessário aos criadores contemporâneos. Diante da multiplicação dos cenários da moda, o escândalo é utilizado por eles para se diferenciarem uns dos outros. Ao lado dos desfiles que chamam atenção, coleções são desenhadas e produzidas para serem vendidas. Pierre Bergé resume assim os desafios da moda contemporânea: "O setor é mais competitivo hoje. Não é mais uma questão de talento. É uma questão de publicidade, de marketing, de escândalo" (apud WHITE, 1997).

Simone de Beauvoir dizia que "o mais escandaloso dos escândalos é que nos habituamos a eles" (apud FRANCIS; GONTIER, 1979, p. 52). No entanto, sempre será necessário lidar com a força de transgressão do imaginário dos criadores e as flutuações morais da sociedade, como se subentende de Rick Owens quando ele declara: "Organizar tardes dançantes, isso é o que se deveria fazer. 0 que poderia ser mais extremo e mais transgressor do que isso?" (RICK, 2006). Os criadores sempre encontrarão novas formas de serem escandalosos. 


\section{NOTAS}

${ }^{1}$ Artigo traduzido pela equipe editorial da revista dObra[s].

${ }^{2}$ Esta é uma versão em português do artigo "Incompréhensions, malaises, scandales dans la mode contemporaine", originalmente publicado no catálogo da exposição Tenue correcte exigée! Quand le vetêment faitscandale, em cartaz no Museu de Artes Decorativas em Paris de 1 de dezembro de 2016 a 23 abril de 2017, sob direção de Denis Bruna.

${ }^{3}$ Costureiro superstar (Couturier superstar) é o título de uma exposição apresentada pelo Museu de Artes Decorativas de Paris, de 5 de junho a 29 de setembro de 2002.

${ }^{4} 0$ vídeo do desfile pode ser visto em https://www.youtube.com/watch?v=Gw9T2_kceVM. Acesso em: 11 abr. 2015.

${ }^{5}$ No original, "Comme des bossus". 0 jornalista associa as deformações das peças a "corcundas", fazendo um jogo de palavras com o nome da grife - "Comme des Garçons" (que, em português, seria "Como Rapazes") - e igualmente uma referência à obra 0 corcunda de Notre-Dame, de Victor Hugo [N. da T.].

${ }^{6}$ Obra de teoria do conhecimento do filósofo alemão Immanuel Kant, publicada pela primeira vez em 1781 [N. da T.].

${ }^{7}$ Projeto artístico do casal Christo Yavachev e Jeanne-Claude Denat de Guillebon [N. da T.].

8 "[...] Gaultier 'is a mensch". Tradução do autor, que agradece a ajuda de Eleanor Yadin, da New York Public Library.

\section{REFERÊNCIAS}

BERGEN, Véronique. Le Corps glorieux de la top-modèle. Fécamp: Nouvelles Éditions Lignes, 2013.

BETTS, Katherine. Best and Worst of 1997. Vogue US, jan. 1998, p. 148-155.

BLAIN, Jean. Vous avez dit... politiquement correct? L'Express, 1 dez. 2012.

CALETTI, Faust. Torse nu. L'exhibition du corps: entre mode et rock. In: MIGLIETII, Francesca Alfano. Le Choc du chic. Conversations sur la mode. Milan: Skira, 2006.

CHAYETTE, Sylvie. Le retour du porno... chic? Effets de mode, 6 maio 2008.

COHEN, Debra Nussbbaum. Chasidic chic' is the "in" look. The American Israelite, 6 maio 1993.

DAYAN, Phillippe. Docteur John et Mystère Galliano. Madame Figaro, 21 jan. 2006, p. 44-46.

DETAILS, mar. 1990, p. 180.

DUKA, John. Paris is Yesterday. New York Magazine, 13 nov. 1978, p. 111-114.

EVANS, Caroline. The Enchanted Spectacle. Fashion Theory, Oxford Berg Publishers, v. 5, n. 3, p. 271310, 2001. Disponivel em: https://doi.org/10.2752/136270401778960865. Acesso em: 3 jan. 2019.

FRANCIS, Claude; GONTIER, Fernande. Les Écrits de Simone de Beauvoir: la vie, l'écriture, avec en appendice, textes inédits ou retrouvés. Paris: Gallimard, 1979.

GROUSSET, Véronique. Parcours choc par pub chic. Le Figaro Magazine, 13 abr. 2001, p. 86.

GRUMBACH, Didier. Une histoire institutionnelle des défilés de mode. In: Showtime. Le défilé de mode, cat. exp., Paris, musée Galliera, 3 mars - 30 juillet 2006. Paris: Paris-Musées, 2006. p. 129-143.

HAYE, Amy De la; MENDES, Valerie. La Mode depuis 1900. Paris: Thames \&t Hudson, 2011[2000]. Collection L'Univers de l'art.

HENNO, Martine. La styliste qui fait scandale, les pyjamas rayés de la marque Comme des Garçons retirés de la collection. Le Figaro, 6 fev. 1995, p. 42.

HORYN, Cathy. Galliano, Still the Master Showman. The New York Times, 10 out. 2005.

HUME, Marion; BLANCHARD, Tamsin. A Little Bit of Fancy. The Independent, 17 mar. 1995.

HUON, Julie. De Rick Owens à Hussein Chalayan: quand les créateurs choquent. Le Soir, 27 jan. 2015.

J. S. Thierry Mugler a vu Microcosmos. Le Figaro, 1997.

JEAN-PAUL Gaultier. Pour ne pas oublier... Actualité juive, 1 abr. 1993. Actu J Femme. 
LEFORT, Gérard. Automne-hiver au masculin. Chiffons. Yamamoto et Gautier, un dialogue tiré à quatre épingles. Libération, 7 fev. 1986, p. 18-19.

LEFORT, Gérard; BOULAY, Anne. Défilés du prêt-à-porter printemps-été 1997: Issey Miyake, signes de plaisir, le créateur japonais va à l'essentiel, Kawakubo réfléchit trop, Bergére est serein-chic. Libération, 10 out. 1996.

LORIOT, Thierry-Maxime. La Planète mode de Jean-Paul Gaultier: de la rue aux étoiles, cat. exp. Montréal: musée des Beaux-Arts de Montréal; Dallas: Dallas Museum of Art; San Francisco, Fine Arts Museums; Madrid: Fundación Mapfre-Instituto de cultura; Rotterdam, Kunsthal; Paris: La Martinière, 2011.

L'UNIVERS des femmes-insects de Thierry Mugler. France Antilles, 1997.

MANESCEAU, Jacqueline; PAILLE, Élisabeth; SEZE, Sabine de. Des défilés, pour quoi faire? Dépêche Mode, p. 24-28, mar-abr., 1987.

MOKO Use Rude. Evening Post, Wellington, 23 jan. 1999.

MÜLLER, Florence. Mode. In: RONY, Anne. Les Années 80. Paris: Éditions du Regard, 1995.

OFFERLÉ, Michel. Sociologie des groupes d'intérêts. Paris: Montchrestien, 1998.

ON en parle. Merce et Rei. Vogue Paris, dez. 1997-jan. 1998, p. 44.

PFEIFFER, Alice. Vous n'y échapperez pas. Le zizi au vent. Les Inrockuptibles, 4 fev. 2015.

RACHLINE, Sonia. Hussein Chalayan: sens et sensualité. Vogue Paris, fev. 1998, p. 94.

RIBEIRO, Aileen. Dress and Morality. Oxford: Berg Publishers, 2003.

RICK Owens. Numéro, mar. 2006, p. 356-361.

ROMILLAT, Sophie. Pyjamas rayés: Commes des Garçons piégé dans son sommeil. Info Matin, 8 fev. 1995, p. 24.

SAINDERICHIN, Ginette. Le bonze et la kamikaze. Le Jardin des modes, dez. 1982, p. 5.

SAMET, Janie. Une tempête dans un dé à coudre. Le Figaro, 27 jan. 2000, p. 16.

SÉPULCHRE, Cécile. La mode provocation de Martin Margiela commence à percer. Journal du textile, 12 jun. 1989, p. 28.

SPINDLER, Amy M. Patterns. The New York Times, 16 mar. 1993a.

SPINDLER, Amy M. Piety on Parade: Fashion Seeks Inspiration. The New York Times, 5 set. 19936.

W IN WONDERLAND. Talk | Rick Owens' Outrageous Nudity Collection [...] \#dickowens http:// wp.me/p59X8t-1Kp. 29 de janeiro de 2015. Twitter: @WilmkeBoersma

WHITE, Constance C. R. Hussein Chalayan's High-Wire Act. The New York Times, 21 abr. 1998.

WHITE, Constance C. R. Patterns: A Movie Point of View. New York Times, 2 dez. 1997. 